\title{
An Expert System for Construction Planning
}

\author{
by Chris Hendrickson ${ }^{\text {}}{ }_{3}$ A.M. ASCE Carlos Zozaya-Gorostiza ${ }^{2}$, \\ Daniel Rehak ${ }^{3}$, Eduardo Baracco-Miller ${ }^{2}$, and \\ Peter Lim ${ }^{2}$
}

May 1987

\begin{abstract}
Among other concerns, construction planning involves the choice of construction technology, the definition of work tasks, the estimation of required resources and durations, the estimation of costs, and the preparation of a project schedule. A prototype knowledge intensive expert system to accomplish these tasks. CONSTRUCTION PLANEX, is described in this paper. This system generates project activity nctw'orks. cost estimates and schedules, including the definition of activitics, specification of precedences. selection of appropriate technologies and estination of durations and costs. The CONSTRUCTION PLANEX system could be useful as an automated assistant in routine planning, as a laboratory for the analysis and craluation of planning strategies, and as a component for more extensive construction assistance systems involving design, site layout or project control. The current application for CONSTRUCTION PLANEX is to plan modular high rise buildings, including excavation, foundation and structural construction.
\end{abstract}

\section{Key Words}

Construction, Planning, Computer Applications, Expert Systems, Scheduling, Project Management

${ }^{1}$ Prof., Dept. of Civil Engr., Carnegie Mellon Univ., Pittsburgh, PA 15213

2Res. Asst, Dept. of Civil Engr.. Camegie Mcllon Univ.. Piusburgh, PA 15213

${ }^{3}$ Assoc. Prof., Dept of Civil Engr., Camegic Mellon Univ., Piusburgh, PA 15213 


\section{Introduction}

Construction planning is a fundamental and challenging activity in the management and exccution of construction projects. It involves the choice of construction technologies, the definition of work tasks, the estimation of the required resources and durations for individual tasks, and the identification of any interactions or constraints among the different tasks. A good construction plan is the basis for developing the project budget and the schedule of work. Poor estimates or schedules can easily result in large construction cost increases or delays. Inappropriate or inconsistent decisions concerning the appropriate technologies to use can have similar effects. As a result, construction planning is crucial to the eventual success of a project.

Current construction planning relies upon manual formulation of plans and is usually performed in an intuitive and unstructured fashion with considerable reliance on engineering judgment. Few computer based aids for activity scheduling exist other than general project templates or past project networks that can be adapted to the particulars of a new project. Commercial scheduling systems require a complete construction plan as an input. Descriptions of the characteristics of good project plans exist in the literature (see, for cxample, (Willis, 1986)), but little attention has been paid to analyzing the process by which plans are or should be formed (Baracco-Miller, 1987).

In this paper, a knowledge intensive expert system for construction project planning is described. The system generates project activity networks, cost estimates and schedules, including the definition of activities, specification of precedences, selection of appropriate technologies and estimation of durations and costs. The system includes three major components:

1. hierarchical representation structures to record information about project activities and decisions made during the planning process;

2. a set of operators to perform specific planning tasks such as technology choice, activity duration estimation, or scheduling; and

3. a store of knowledge sources to provide relevant information for operations.

Experience with a prototype of the overall system is also described. This prototype plans activities associated with site preparation, excavation, foundation construction, and structural erection for high rise buildings.

The construction planning expert system described here, called CONSTRUCTION PLANEX, is proposed for several reasons. First, this system provides a ricans to formalize the planning process so as to permit analysis and evaluation of different strategies and tasks within the overall process. By formalizing the various decisions and planning strategies, existing 
knowledge can be examined and gaps in knowledge or procedures highlighted. Many expert system development projects have had secondary effects of this sort (Shortliffe, 1976).

Second, the system represents a framework for the development of automated planning assistants based on knowledge-based expert system and artificial intelligence programming techniques. These techniques promise to have a revolutionary impact on construction engineering and management since they greatly expand the capability to manipulate and utilize qualitative and experiential information so prevalent in the construction ficld. In the realm of construction planning, the expert system is likely to work as an assistant to a planner to handle details of planning or to suggest alternatives. With an automated assistant, more detailed and accuratc activity networks should be feasible and cost effective.

Finally, the proposed system might provide a component for more extensive project control systems in which project monitoring or facility design are major goals. By facility design, we include the entire process of architecture and engineering design and facility fabrication. For project monitoring and adaptation of a plan over time, the expert system has the advantage of preserving a record of decision points and hicrarchy among activities so that past decisions can be reviewed and modified in light of new events.

The next section briefly describes some background on the use of expert systems and artificial intelligence in planning. The following section describes the architecture of the CONSTRUCTION PLANEX system. Operation of the system is illustrated with a planning problem for a modular building. A concluding section summarizes preliminary results in the area.

\section{Background}

Numerous applications of expert systems in the realm of construction project management have been suggested; Levitt (Levitt, 1986) provides a general review. Systems for project monitoring (McGartland, 1985), schedule updating (Levitt, 1985), schedule criticism (O’Connor, 1986) and activity duration estimation (Hendrickson, 1987) have been described in the literature. Several expert systems for diagnosis of equipment and other purposes are in routine use (Kostem, 1986). However, no system currently exists for the construction project planning problem (O’Connor, 1987).

In the literature of artificial intelligence, numcrous papers have addressed the general problem of planning, although not spccifically in the context of construction. The most common application area has been in the realm of planning movements of blocks to achieve desired goals. NOAH (for Network of Action Hicrarchies) was an initial formalization of the problem 
in which declarative and procedural knowledge about activities were represented in a nctwork. This system began with a system statement of desired goals represented as a node in a network, and this network was then expanded and modified by defined operators (Sacerdoti, 1974, Sacerdoti, 1977). NONLIN was an extension of NOAH which included a decision graph to permit backtracking and alternative resource decisions (Tate, 1977). DEVISER was intended to plan and schedule an autonomous unmanned spacecraft (Vere, 1983); it contained explicit information on time constraints in the process. MOLGEN also used explicit operators in a hierarchical task space to perform planning of genetic experiments (Stefik, 1981a, Stefik, 1981b). MOLGEN featured a flexible control structure and explicit formalisms for constraints on the activity plan. Finally, the scheduling system ISIS and its successor CALLISTO developed a general system of activity representation within the realm of job shop scheduling (Fox, 1984, Sathi, 1986).

While these artificial intelligence based planning systems offer some useful conceptual tools, each has significant limitations for construction planning. First, these systems generally incorporate only a relatively small number of well defined, repetitive tasks. In contrast, construction requires numerous distinct tasks for completion. Second, construction planning involves the selection of appropriate resources to apply, in contrast to blockworld or job shop scheduling problems in which resources are given. Third, construction has numerous important planning concerns with respect to time constraints, cost and resource trade offs, and spatial restrictions which are not explicitly considered by existing AI planning systems. In particular, the trade-offs between cost, technology and activity duration is important for construction planning but is not considered in existing Al planning models. Fourth, the large size of construction planning problems suggests that efficient, algorithmic scheduling tools may be required rather than relying entirely on myopic, heuristic allocations. The computational burden of scheduling in construction is significant: construction schedules can include hundreds of activities. Fifth, construction planning is highly knowledge intensive, so explicit use of expert knowledge is required in the planning process. Accordingly, a different system architecture is required in the construction domain than occurs in existing AI planning models.

\section{CONSTRUCTION PLANEX Ove Rview}

Similar to other knowledge-based expert systems, CONSTRUCTION PLANEX has three essential parts as illustrated in Figure 1. The Context contains information on the particular project being considered, including the design, site characteristics, the planning decisions made, and the current project plan. The Operator Module contains operators that create, delete or modify the information stored in the context. Operators are used for different tasks such as technology choice, activity synthesis, duration cstimation and others. The Knowledge-Base 
contains distinct knowledge sources of tables and rules specific to particular technology choices, activity durations, or other considerations. In addition to these three components, CONSTRUCTION PLANEX contains a menu driven interface used to control the execution of the operators and a Knowledge Source Acquisition Module used to modify the contents of the Knowledge Base. The system is implemented in KNOWLEDGECRAFT ${ }^{\mathrm{TM}}$ on a Texas Instruments' EXPLORER ${ }^{\mathrm{TM}}$ computer.

In the Context, information is stored in a series of hicrarchically organized frames. Each frame is linked to parent or children frames from which information can be inherited. Frames are named and contain various slots to record information. As an example, Figure 2 shows a frame for an individual design element consisting of a column footing. This frame is titled "p01-s00-b00-f00-de-60-01-01" and contains four types of slots:

- Classification Slots that identify the type of design element. CONSTRUCTION PLANEX uses a design code to identify design elements. In particular, is- $a$ is used to indicate that this frame is a design element frame, the slot name-code with value 60 indicates that this design element frame corresponds to a column footing, the slot type-element with value 01 indicates that this is a concrete footing and the slot number-element indicates that this is the first of several concrete column footings.

- Location Slots that specify in what project, sector, block and floor is located the particular design element. Also, there are slots such as $x g$-coordinate, yg-coordinate and $z$ g-coordinate that specify the global coordinates of a point of the design element.

- Geometry Slots that describe the geometric characteristics of the design element such as $x l$-coordinate, $y l$-coordinate, zl-coordinate, $x$-angle, $y$-angle and $z$-angle. Geometry slots may be named differently (for example $y$-coordinate could be named width); also, each type of design element has its own set of geometry slots.

- Specifications Slots that contain other information concerning the design element relevant to the planning process. For example, the construction-type and the concrete-type are useful specifications for determining appropriate construction technologies.

Design elements of this type would be basic inputs to the planning system.

During operation of the system, additional frames are created to represent activities and decisions. For example, Figure 3 illustrates a frame created to describe the excavation activity required for the column footing described in Figure 2. Attributes describing this activity include:

- Classification Slots that identify the type of element activity. CONSTRUCTION PLANEX uses an extended MASTERFORMAT code (CSI, 1983) to identify element activities. For example, the ea-code of this activity indicate: that it belongs to Division 2 (Sitework) of the MASTERFORMAT, to Broadscope 220 (Excavation, Backfilling \& Compacting) and to Narrowscope 10 (Column Footing). 
- Hierarchy Slots that specify the relationships between the element activity frame and other frames of the context. For example. the ea-of-DE slot is used to identify the design clement for which this activity takes place, the parent-L:A slot indicates a pointer to a parent frame common to several element activitics of the same MASTERFORMAT code and the parent- $P A$ slot indicates a pointer to a higher aggregation of construction activities.

- Quantity-Take-Off Slots that contain information about the amount of work and the unit-of-measure for the element activity.

- Specification Slots that describe other information relevant to the activity such as the type of material-package that has to be used. The information of these slots might be common to several element activities. If this is the case, the system stores this information in higher levels of the hierarchical frame structure.

- Technology-Decision Slots containing information about technology choices such as the type of crew to be used. In the general case, technology information is inherited from other frames in the context as described below. However, the user may override this values and specify technology choices at the level of element activities.

- Technology-Consequence Slots that describe information dependent upon the technology choice affecting the element activity, such as the duration of the activity, its successors and its cost.

Element activities do not represent an appropriate level of detail for planning purposes. Construction planners work with more aggregated activities that involve several element activities of similar nature. These aggregated activities are used to create the project network that is used as the basis for technology choices and for. scheduling purposes. Figure 4 illustrates a project activity frame. Slots in this frame include:

- Classification Slots that identify the type of project activity. CONSTRUCTION PLANEX uses an internal pa-code for classifying project activities.

- Hierarchy Slots that specify the relationships of the project activity frame in the context such as the pa-has-eas slot that contains pointers to all the element activities belonging to the project activity and the parent-PA slot that points to a group of project activitics of similar characteristics.

- Quantity-Take-Off Slots that contain information about the amount of work and the unit-of-measure for the project activity. The amount of work of a project activity is obtained by aggregating the quantities-take-off of its element activities.

- Specification Slots that describe other aggregated information such as the quantity of materials required to perform the activity.

- Technology-Decision Slots containing information about the type of crew and number of crews allocated to this project activity. The information in the slot number-crews is important because it affects the overall duration of the activity and the sequence in which its element activities are performed.

- Technology-Consequence Slots that describe information such as duration, cost, successors and successor lags. 
- Scheduling Slots that describe scheduling information such as the earliest and latest start time of the activity and the milesiones imposed on the activity.

Project activity slots as well the various slot attributes are created by the CONSTRUCTION PLANEX system.

These different frames are organized to represent the current project plan, decisions made during the planning process, and different aggregation schemes. Figure 5 shows the general structure of the context. On top of the hicrarchy there are frames used to store information at the project, sector, block and floor levels. Below them there are trees for design elements, element activities and project activities. Element activities are linked to design elements, to element activity groups and to project activities. Decisions and computations undertaken during the planning process can be stored in any of the frames of this hierarchy and inherited by element activities. Furthermore, inherited values can be overridden by local decisions for particular cases. Thus, the set of activities can form a conventional project network while the system context contains a more extensive network which also records the planning process and other information.

The operator modules alter the system context by creating frames or modifying attributes. The exact modifications made are found by evaluating relevant knowledge sources in the knowledge base. In the initial creation of a construction plan, the following sequence of operations might be followed:

- Create Element Activities for design elements. This operation only identifies the set of element activities required to accomplish each design element. Other information is added to element activity frames using other operators.

- Group Element Activities of common characteristics in order to have a hierarchy of element activities similar to that of the MASTERFORMAT.

- Determine Amounts of Work for element activitics. Gcometric information is inherited from design element frames.

- Select Units of Measure for element activities. Crew productivities or material quantities may be expressed in different units (eg. days instead of hours). In these cases, the system performs appropriate unit conversions.

- Determine Material Packages for element activities. Material Packages should satisfy design specifications.

- Create Project Activities that aggregate element activities.

- Determine Precedences for project activities. Project activitics can be structured into a projecı network.

- Compute Lags for project activities. Element activitics of several project activities are structured into an element activity subnetwork. A simple CPM algorithm is used 
to determine scheduling information in this subnctwork. This information can be analyzed to compute lags between aggregated project activities.

- Select Technologies for project activities. For this operation the system uses heuristics related to soil and site information, resource productivity information and other factors (such as weather). Dependent choices are expressed by creating auxiliary frames pointing to several project activities.

- Estimate Durations for project and element activities. Standard productivities of selected resources are adjusted in order to estimate the duration of construction activities.

- Schedule project activities using CPM, resource allocation and constraint satisfaction algorithms.

- Estimate Costs by computing activity costs and project costs using unit costs and scheduling information.

The knowledge base is organized into a set of knowledge sources (KS) that represent rules, heuristics, and calculation functions. These knowledge sources can best be pictured as decision tables, although they are actually written as frames and production rules. An example of a knowledge source appears in Figure 6. This KS contains two conditions, 3 rules and 3 actions. The first rule indicates that if the soil-type is hard and the result of evaluating $K S$-water-level is not wet, then the appropriate technology is power-shovel. The second rule indicates that if the soil-type is not hard and the result of evaluating $K S$-waterlevel is wet, then the appropriate technology is clamshell. Finally, the third rule indicates that if none of the previous two rules were fired, the appropriate technology is special-machine.

When performing the operations described previously, the system evaluates numerous $\mathrm{KS}$ using two types of generic operators:

- Knowledge Source Evaluator (KSE). This operator is used to determine results of KS that affect leafs or subtrees of the context. For example, activity duration estimation is an operation that affects only single activities. For this operation, the KSE is used to consult a knowledge source specific to each narrowscope activity.

- Knowledge Source Evaluator with Grouping (KSEG). This operator is used to determine results of KS that affect frames of different subtrees of the context. For example, selecting the type of equipment to be used for pouring concrete in columns of a particular floor might constrain the type of equipment to be used in similar activities of other floors.

In designing the CONSTRUCTION PLANEX system, our goal was to create a flexible and generic framework for knowledge intensive activity planning. By substituting different knowledge sources, the system is capable of application to different types of projects. 


\section{Prototype Overview: Modular Buildings}

The current version of CONSTRUCTION PLANEX does not interact with any computer aided design system. The system reads input files with information about individual design elements such as the one presented in Figure 2. However, providing the system with geometric information about every design element of a building is a cumbersome task, especially in high rise buildings. While the PLANEX system can handle an arbitrary design, we have created an input program that receives information about the design elements of a module of the building and uses this data to generate the project plan for the whole building. An example of such module is illustrated in Figure 7. This module contains 4 column footings, 4 columns, 4 beams and 1 slab. The input file of this module would have 13 design element frames. The current user interface is relatively crudc, consisting of menus, text messages and a limited number of graphs.

Once the basic module of the building has been created, the user specifies the characteristics of the building in terms of this basic module. First, the user specifies the number of identical modules in the $\mathrm{x}, \mathrm{y}$ and $\mathrm{z}$ directions. With this information, the system creates frames for each type of design element with information for the whole building. Then, the user may modify instances of the basic module in order to allow buildings with variable spacing between columns or floors. An example of a modular building is presented in Figure 8. This building is composed of $4 \mathrm{X} 4 \mathrm{X} \mathrm{n}$ identical modules sharing some common design elements.

The second task is to create. element activities for each design element. The schema representation of a knowledge source that can be evaluated in this process, $k s$-create-ea-60-1, is displayed in Figure 9. Seven of the following eight element activities may be needed for a column footing: excavation, dispose-off-excavation, formwork, reinforcing-steel, pour-concrete, remove-forms, borrow-material and pile-up. The pile-up and borrow-material activities are exclusive. The latter is needed when the soil is inappropriate for backfilling.

The next task is to perform operations on the element activity frames. First, the system structures them hierarchically and then it computes the amount of work and the unit of measure for each element activity. The KS to obtain quantities return formulas that have to be evaluated subsequently. These formulas are written in non LISP code to make them more readable. For example, formula- 03 is:

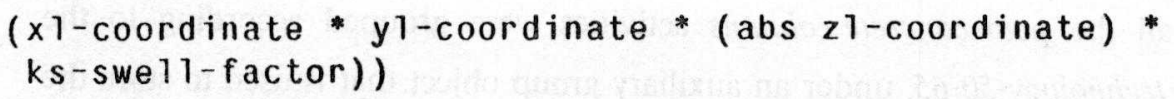

During the evaluation of this formula, the system must evaluate $k s$-swell-factor to obtain the adjusted volume. 
The third task is to aggregate element activities into project activitics. The system performs this task by evaluating a KS for each narrowscope frame of the element activity trec. The output for some of the remove-forms clement activities is the following:

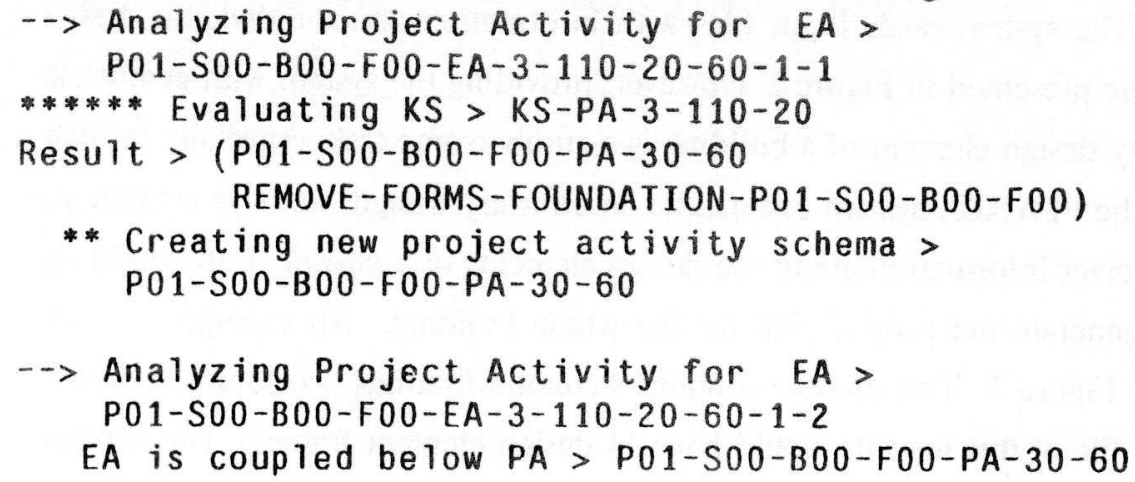

At this point, the system generates project tasks for other floors, blocks, and sectors of the project. The number of project activities created depend on the initial specification of the modular building.

Once the different project tasks are created, a variety of subsidiary decision and estimation problems are addressed. These problems include determining the equipment to be used, the number of crews or pieces of equipment, inter-task precedences, and task durations. In contrast to the synthesis involved in activity definition, these tasks involve diagnosis and prediction.

For equipment choice, a set of KS are included to recommend a particular type of equipment based on characteristics of the site and the required elements of work. Equipment recommendations made by the system can be reviewed and over-ridden by the user. For example, the PLANEX output for a technology choice might be:

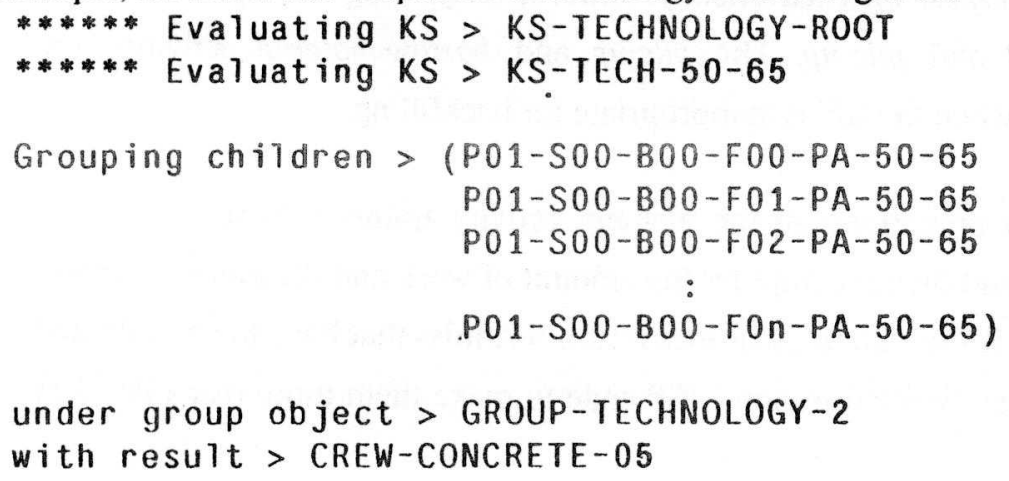

In this example, all the pour-concrete-columns activities were grouped according to the conditions of KS ks-technology-50-65, under an auxiliary group object that is used to store the common technology choice.

Task durations are estimated from decision tables and calculating rules in a manner similar to 
that used in the MASON system (Hendrickson, 1987). In that system, a basic productivity is estimated and then modified in light of specific conditions of a job. In the prototype, productivitics are modified for different equipment types and other special problems. Recommendations for improving task productivity could also be provided as in the MASON system, but this capability is not provided in the prototype.

Precedences among element activities are also determined and recorded in slots of the element activity frames. These precedences can be of two types: (1) physical or (2) resource related. Physical precedences are based on necessary sequences of activities for particular project activities and clement of work. For example, completion of the excavation task must precede formwork activities on a design element. Resource related precedences are obtained by assigning the sequence in which a particular machine or crew would undertake different element activities. These resource allocation decisions are made by a set of rules based on an appropriate starting point and the spatial orientation of design elements. In a more extensive system, these resource allocations could be made by means of heuristic rules prior to scheduling or as part of the application of a resource constrained scheduling algorithm. An example output for the precedence identification at the level of project activities is the following:

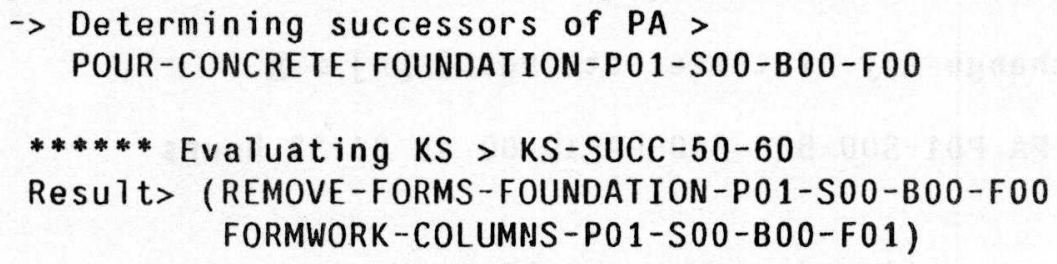

The output of the prototype system during the computation of the appropriate number of crews and adjusted duration of project activities is the following (input from the user is underlined):

$-\rightarrow$ Determining duration of $P A>$ EXCAVATION-FOUNDATION-P01-SOO-BOO-FOO

****** Evaluating KS > KS-DURA-10-60

No knowledge has been given for computing the set of productivity factors

The system assigns to activity

EXCAVATION-FOUNDATION-P01-S00-B00-F00

a default duration of 10 days.

Number of crews needed to satisfy this duration are 1.04 crews of type CREW-EXCAVATION-05 


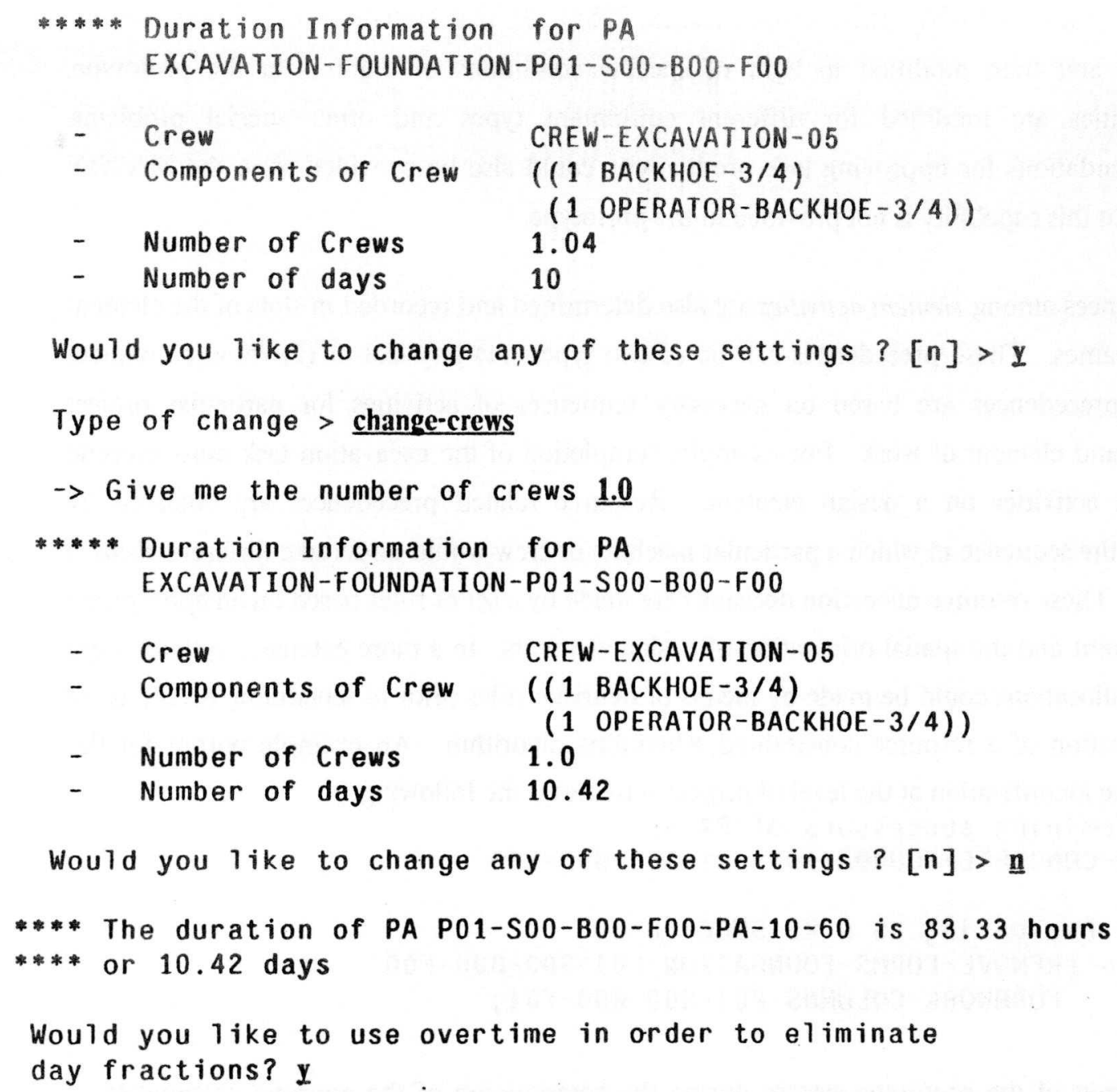

At this point, the system divides the total duration into 10 days of normal hours and 0.42 days of overtime hours.

Application of a critical path scheduling algorithm is a final utility available in the prototype PLANEX system. Once project activities, precedences and durations are identificd, this scheduling procedure is straightforward. With an initial schedule and plan, the user can then revise the allocation of machinery or the number of resources available to achieve desired goals. Figure 10 shows a typical project activity network obtained with the prototype system. 


\section{Conclusion}

We have described the architecture and function of a knowledge-based expert system for construction planning. Applications of the prototype to modular buildings demonstrated the feasibility of the system in that activity networks were developed automatically, durations estimated, and a project schedule obtained. A number of features of the system are notable. First, the development of the system led to a more formal description of the construction project planning process. CONSTRUCTION PLANEX is the first knowledge-based system that emulates the complete construction planning process. Second, the architeciure of the system is modular, and this makes it flexible and easily applicable for other types of construction projects. The prototype system incorporated numerous knowledge sources to perform technology choice, duration estimation, precedence setting and activity identification in the domain of office building projects. Third, during the planning process, the system develops and maintains a context with an extended description of a construction plan including hicrarchies of design elements and work activities, as well as constraints on items such as resources, technology choices and milestone completion dates. Decisions undertaken during the planning process are also represented in the context in a hierarchical manner. This provides the system with the capability of backtracking previous decisions and providing explanations to the user about outcomes of particular tasks. The hierarchy of project activities provides a detailed work breakdown but also represents appropriate aggregations of activities along with resource availability and technology choice at appropriate levels of aggregation. The design element hierarchy also provides a representation at different levels of abstraction that may be useful for integration with three dimensional computer aided design systems. This plan context provides a much richer description of the construction process and available options than does traditional activity networks.

While the feasibility of an automated planning system has been demonstrated, the desirability of an expert system of this sort is still an open question. Considerably more experience with the system will be required, especially field testing. However, the potential benefits of the system could be substantial.

\section{Acknowledgements}

Financial support for this research from the National Science Foundation under grant number MSM-8503400 is gratefully acknowledged. 


\section{Appendix-References}

Baracco-Miller, E. (May 1987). Planning for Construction. Master's thesis, Department of Civil Engr., Carnegic Mcllon University,

The Construction Specifications Institute. (1983). MASTERIORMAT - Master List of Section Titles and Numbers. Relcasing Industry Group.

Fox, M.S. and Smith, S.F. (July 1984). ISIS: A Knowledge Based System for Factory Scheduling. The International Journal of Knowledge Engineering, 1, 25-49.

Hendrickson, C.T., Martinelli, D. and Rehak, D. (June 1987). Hierarchical Rule-Based Activity Duration Estimation. ASCE Journal of Construction Engineering and Management, $113(2), 288-301$.

Kostem, C. N. and M. L. Maher (Editors). (1986). Expert Systems in Civil Engineering. New York, NY.: American Society of Civil Engineers.

Levitt, R.E., and Kunz, J.C. (December 1985). Using Knowledge of Construction and Project Management for Automated Schedule Updating. Project Management Journal, XVI(5), $57-76$.

Levitt, R.E. (October 1986). Expert Systems in Construction. In Survey of the State-of-the-Art Exper/Knowledge Based Systems in Civil Engineering. Special Report P-87/01, US Army Corps of Engineers, DACW88-85-D-007.

McGartland, M.R. and Hendrickson, C.T. (September 1985). Expert Systems for Construction Project Monitoring. ASCE Journal of Construction Engineering Management, 111(3), 293-307.

O'Connor, M.J., De la Garza J.M. and Ibbs, C.W. (1986). An Expert System for Construction Schedule Analysis. In Expert Systems in Civil Engineering, Eds. Kostem, C.L. and Maher, M. L. American Society of Civil Engineers.

O'Connor, M.J. et al. (March 1987). Workshop on Expert Systems for Construction Scheduling (Tech. Rep.). US Army Corps of Engineers, Construction Engineering Research Laboratory, Champaign, Illinois,

Sacerdoti, E.D. ( 1974). Planning in a Hierarchy of Abstraction Spaces. Artificial Intelligence, $5(2), 115-135$. 
Sacerdoti, E.L. (1977). A Structure for Plans and Behavior. Ncw York: Hlscvier-Holland.

Sathi, A., Morton, E. and Roth, S.F. (Winter 1986). Callisto: An Intelligent Project Management System. Al Magazine, 7(5), 34-52.

Shortliffe E.H. (1976). Computer-Based Medical Consultations: MYCIN. New York: American Elsevier.

Stefik, M. (1981). Planning with Constraints (MOLGEN: Part 1). Artificial Intelligence, 16(2), 111-140.

Stefik, M. (1981). Planning and Meta-Planning (MOLGEN: Part 2). Arlificial Intelligence, 16(2), 141-170.

Tate, A. (1977). Generating Project Networks. Proceedings of the Fifth International Joint Conference on Artificial Intelligence. .

Vere, S.A. (May 1983). Planning in Time: Windows and Durations for Activities and Goals. IEEE PAMI, 5(5), 246-259.

Willis E.M. (1986). Scheduling Construction Projects. New York: John Wiley and Sons. 
Operators

\section{Context}

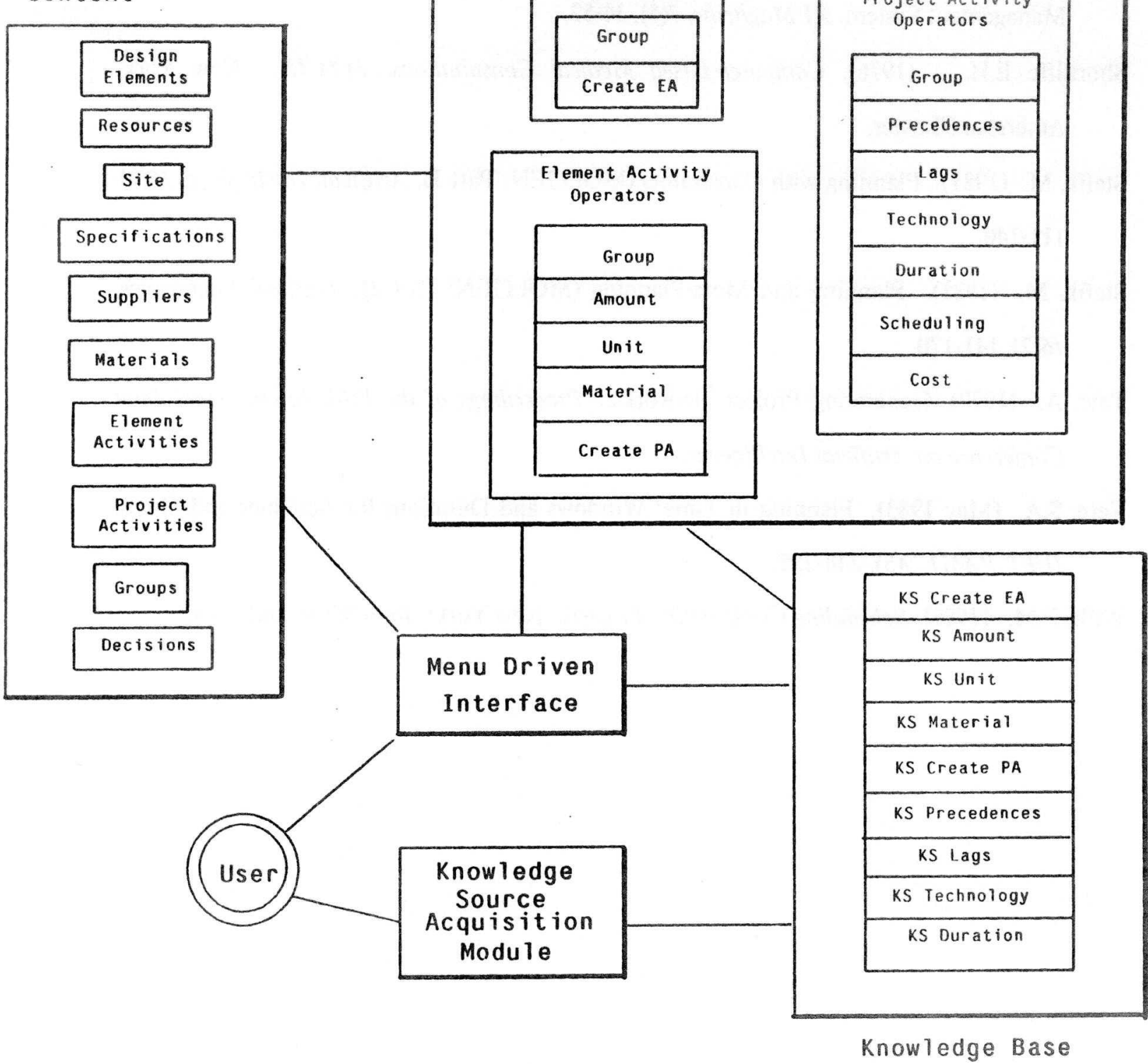

Figure 1: Overview of CONSTRUCTION PLANEX 


\begin{tabular}{|l|l|}
\hline \multicolumn{2}{|c|}{$\begin{array}{r}\text { DESIGN-ELEMENT } \\
\text { p01-s00-b00-f00-de-60-01-01 }\end{array}$} \\
\hline SLOT & VALUE \\
\hline is-a & de \\
\hline name & column-footing \\
\hline name-code & 60 \\
\hline type-element & 01 \\
\hline number-clement & 01 \\
\hline project & p01 \\
\hline sector & s00 \\
\hline block & b00 \\
\hline floor & f00 \\
\hline construction-type & cast-in-place \\
\hline concrete-type & normalweight-3000 \\
\hline re-steel-density & rsd-1 \\
\hline xg-coordinate & 10 \\
\hline yg-coordinate & 10 \\
\hline zg-coordinate & -4 \\
\hline xl-coordinate & 10 \\
\hline yl-coordinate & 8 \\
\hline zl-coordinate & -1.50 \\
\hline$x$-angle & 0 \\
\hline y-angle & 0 \\
\hline$z$-angle & 0 \\
\hline
\end{tabular}

Figure 2: An Example Column Footing Design Element Frame 


\begin{tabular}{|l|l|}
\hline \multicolumn{2}{|c|}{ E01-5.MENT-ACTIVITY } \\
\hline SLOT & VALUE \\
\hline is-a & ea \\
\hline ea-name & excavation-column-footing-01 \\
\hline ea-code & $02-220-10-01$ \\
\hline ea-of-DE & p01-s00-b00-f00-de-60-01-01 \\
\hline parent-EA & p01-s00-b00-f00-ca-02-220-10 \\
\hline ea-of-PA & p01-s00-b00-f00-pa-10-60 \\
\hline amount-of-work & 24.0 \\
\hline unit-of-measure & cu-yd \\
\hline crew & excavation-foundation-05 \\
\hline matcrial-package & none \\
\hline duration & 16 hours \\
\hline successors & p01-s00-b00-f00-ea-02-220-10-02 \\
\hline
\end{tabular}

Figure 3: An Example Element Activity Frame 


\begin{tabular}{|l|l|}
\hline \multicolumn{2}{|l|}{$\begin{array}{l}\text { PROJIEC T-ACTIVITY } \\
\text { p01-b00-100-pa-10-60 }\end{array}$} \\
\hline SLOT & VALUE \\
\hline is-a & pa \\
\hline pa-name & Excavation-Foundation-p01-s00-b00-f00 \\
\hline pa-code & $10-60$ \\
\hline parent-PA & p01-s00-b00-f00-pa-10 \\
\hline pa-has-eas & p01-s00-b00-f00-ea-02-220-10 \\
\hline amount-of-work & 720.0 \\
\hline unit-of-measure & cu-yd \\
\hline crew & Excavation-Foundation-05 \\
\hline number-crews & 1 \\
\hline material-list & none \\
\hline duration & 480.0 \\
\hline successors & p01-s00-b00-f00-pa-20-60 \\
\hline succ-lags & 16 hours \\
\hline EST & day 15 \\
\hline LST & day 15 \\
\hline EFT & day 75 \\
\hline LFT & day 75 \\
\hline
\end{tabular}

Figure 4: An Example Project Activity Frame 


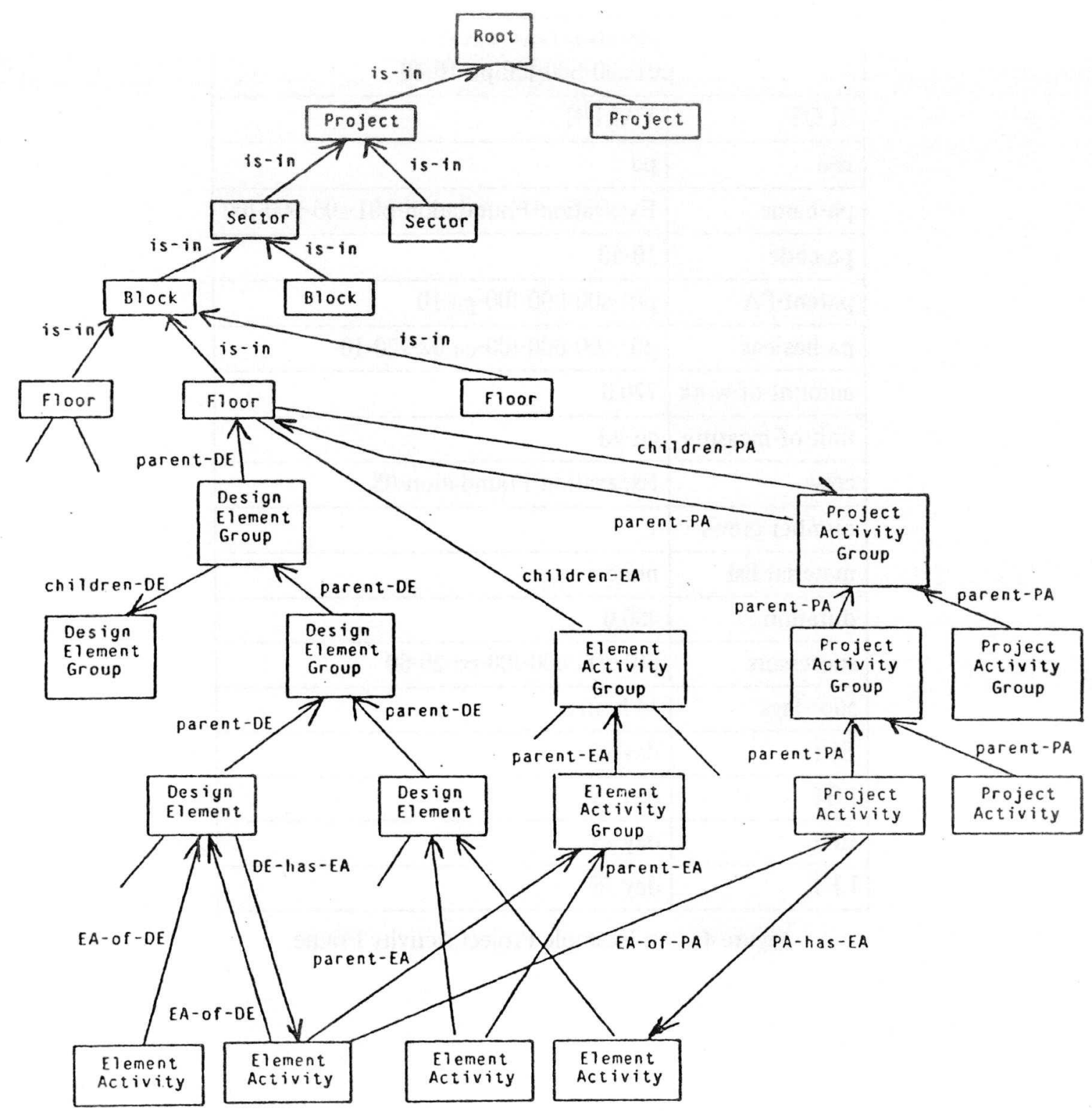

Figure 5: Context Structure in CONSTRUCTION PLANEX 


\begin{tabular}{|l|l|l|l|l|l|l|}
\hline \multicolumn{7}{|c|}{ KS-Technology-Example } \\
\hline Object & Slot & Op & Value & \multicolumn{3}{|c|}{ RULES } \\
\hline soil-characteristics & soil-type & is & hard & t & f & $i$ \\
\hline & KS-water-level & is & wet & i & i & $i$ \\
\hline & power - shovel & & $x$ & i & \\
\hline & clamshell & & & $x$ & \\
\hline \multicolumn{3}{|c|}{ special - machine } & & - & $x$ \\
\hline
\end{tabular}

Figure 6: Example of a Knowledge Source 


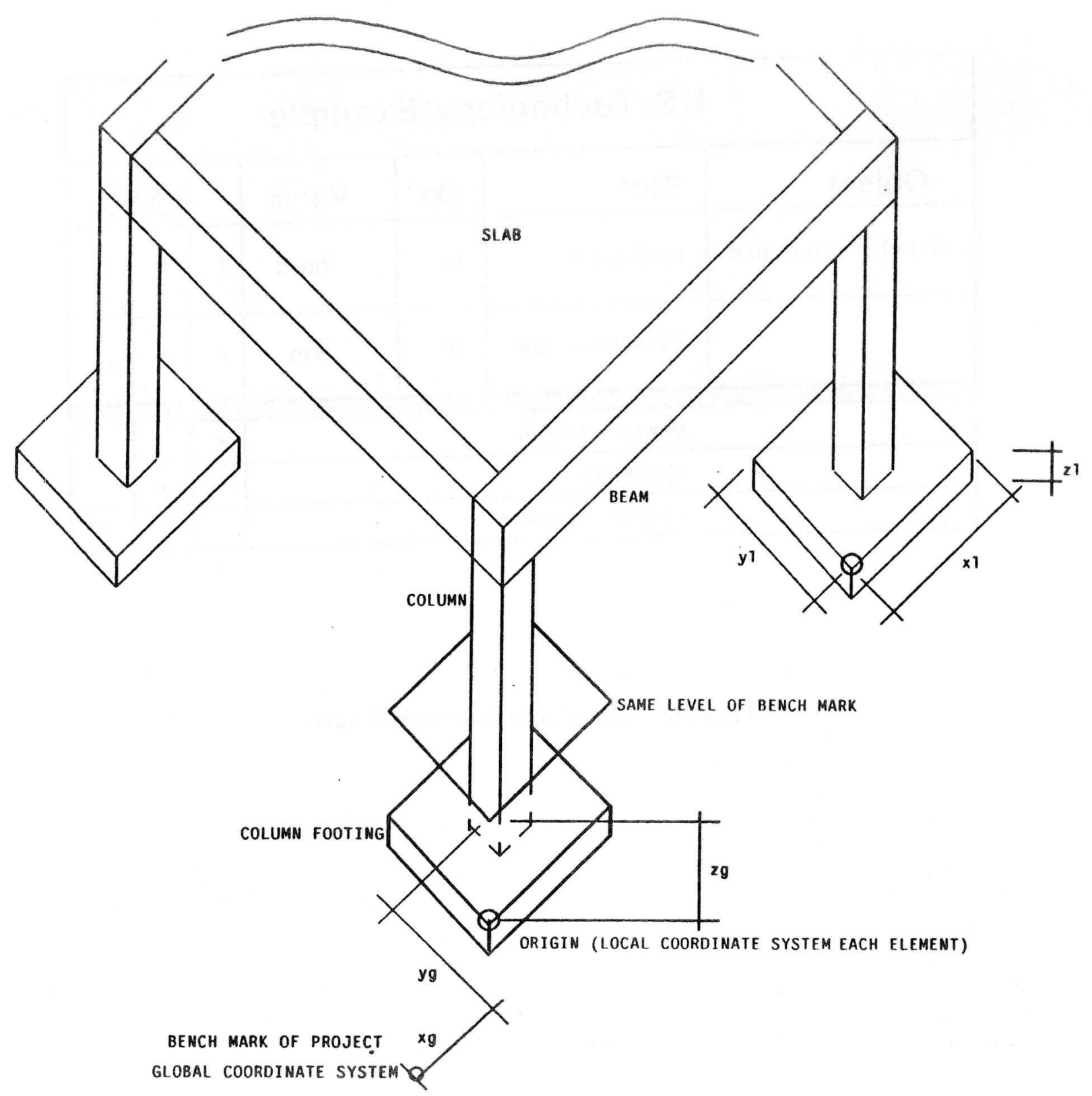

Figure 7: Example of a Basic Building Module 


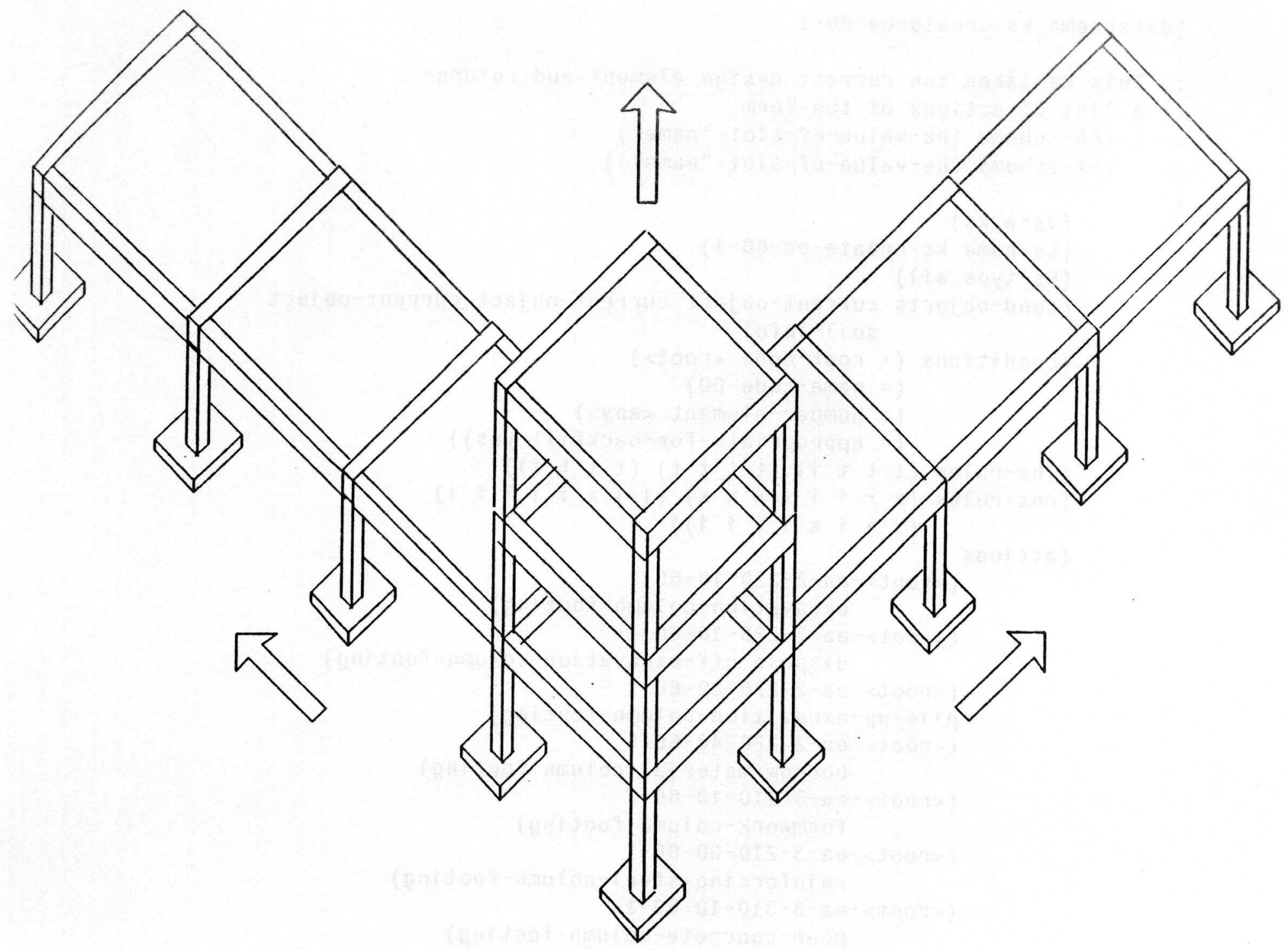

Figure 8: Example of a Modular Building 


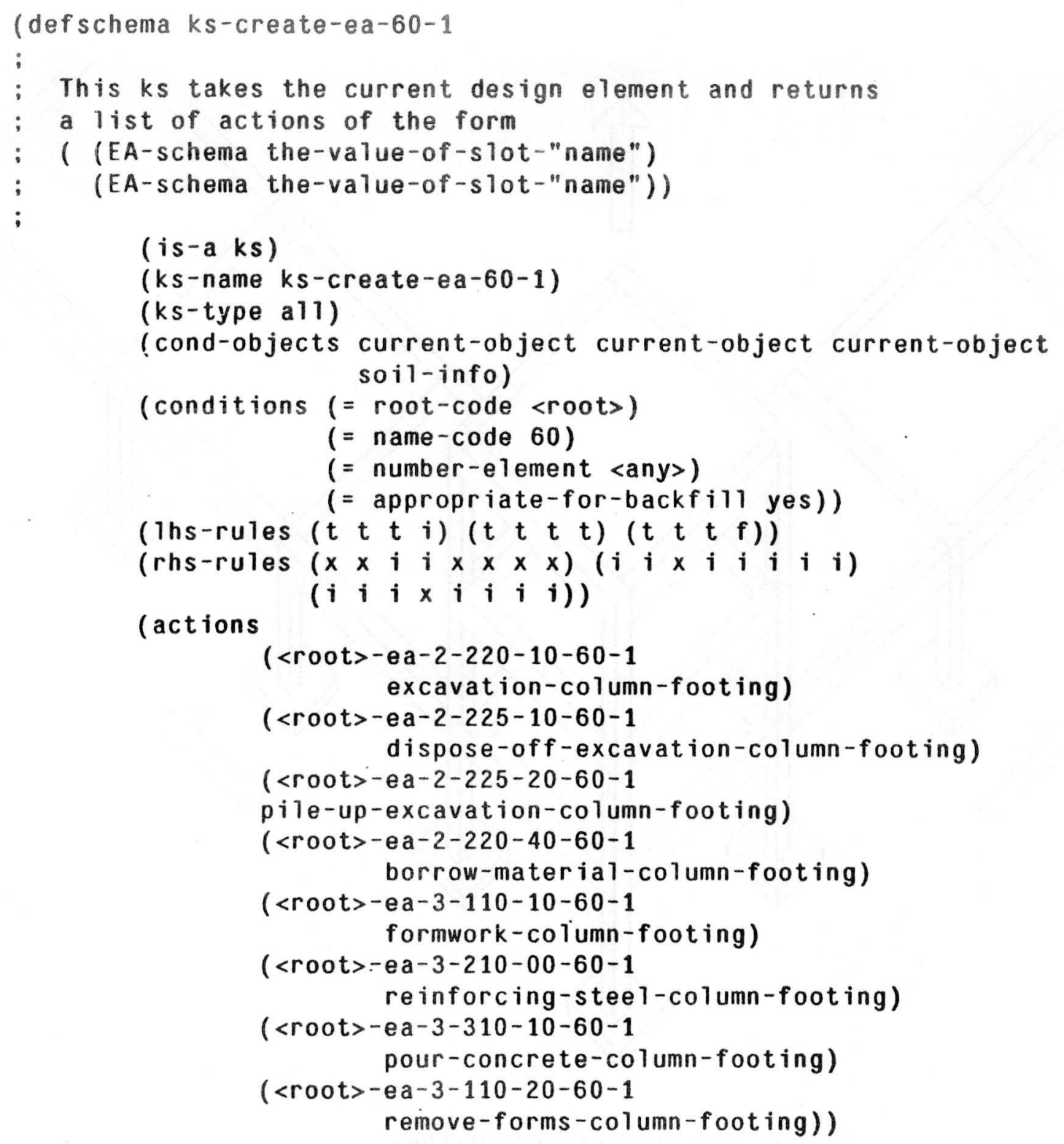

Figure 9: Example of a Knowledge Source for Element Activity Creation 


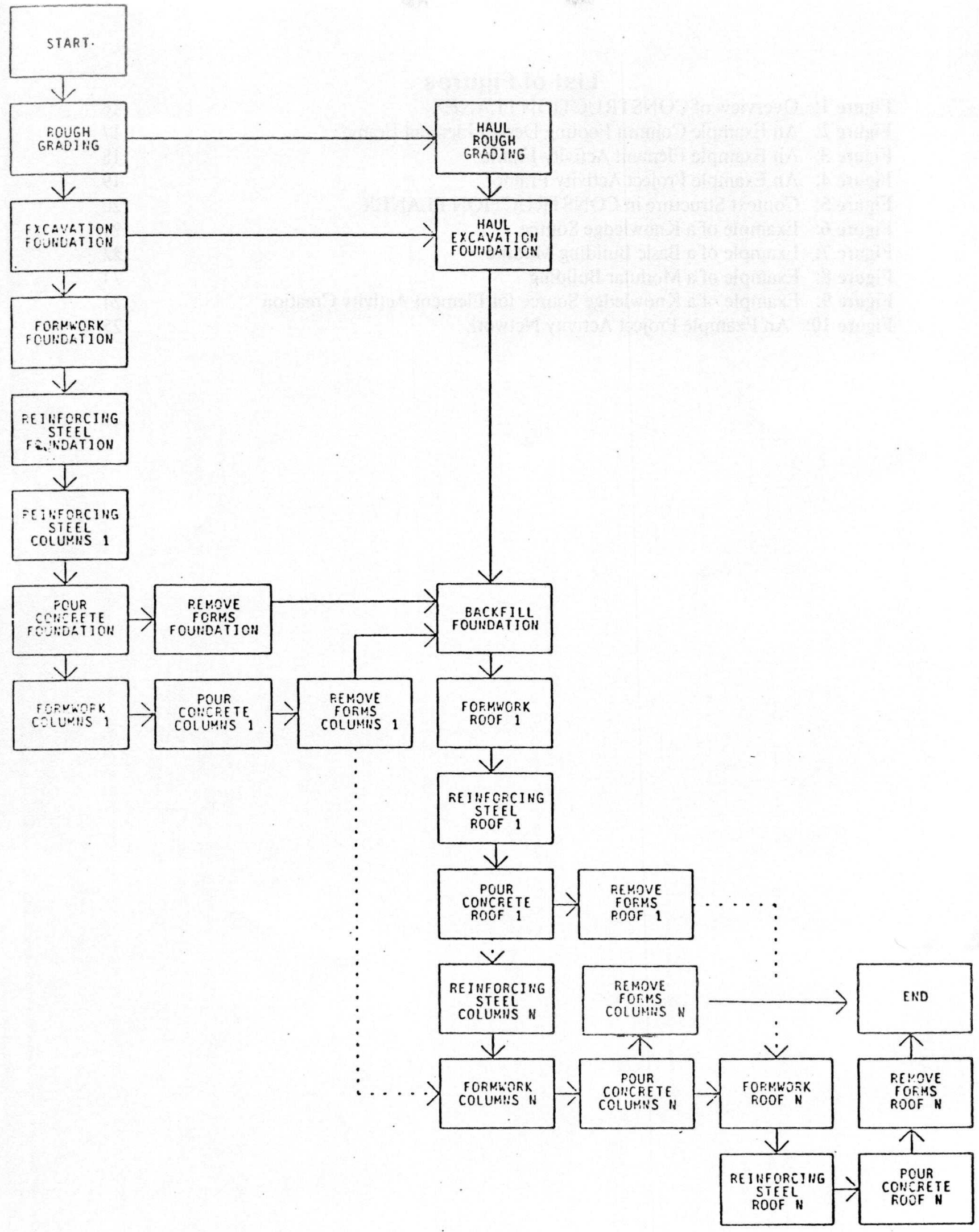

Figure 10: An Examplc Project Activity Nctwork 


\section{List of Figures}

Figure 1: Overview of CONSTRUCTION P'ANEX

Figure 2: An Example Column Footing Design Element Frame 17

Figure 3: An Example Element Activity Frame

Figure 4: $\Lambda_{\mathrm{n}}$ Example Project Activity Frame

Figure 5: Context Structure in CONSTRUCTION PLANEX 20

Figure 6: Example of a Knowledge Source

Figure 7: Example of a Basic Building Module 22

Figure 8: Example of a Modular Building

Figure 9: Example of a Knowledge Source for Element Activity Creation

Figure 10: An Example Project Activity Network 